\title{
AN OPTIMIZED AGILE TECHNIQUE TO EFFECTIVELY IMPLEMENT AGILE METHODS IN PROJECT MANAGEMENT: A RESEARCH PROPOSITION
}

\author{
Rosarito Sánchez-Morcilio, University of Puerto Rico, Río Piedras Campus, rosarito.sanchez@upr.edu \\ Francisco Quiles-Torres, University of Puerto Rico, Río Piedras Campus, francisco.quiles@upr.edu
}

\begin{abstract}
Discerning the most relevant information about agile project management can become overwhelming since there is plenty of material available. This study provides a synthesis of the literature review to find out guidance on how to implement agile methodologies to manage projects adequately. An optimized agile technique (OAT) is proposed for achieving agile methodologies to successful project management. OAT suggests selecting the right agile tools, authenticating quality to create a value-added outcome for customers, and establishing frequent targeted meetings among working teams, as communication is still the principal success factor in project management, especially in agile environments.
\end{abstract}

Keywords: Agile methodologies, agile technique, Project Management, Software Development, agile optimization

\section{INTRODUCTION}

The CHAOS Report (Johnson, 2018) presents software project performance from a massive data collection that includes over 50,000 project profiles from 2013 to 2017. Software projects are regularly related to innovation. Organizations in general often focus in the management of innovation projects in order to provide their clients the best services and products. These projects require a high degree of creativity and flexibility from the project team members; traditional practices may negatively coerce novelty. Innovation encourages new approaches to management (Birkinshaw, 2018). Agile methodologies are a set of procedures that offer better ways to approach the fastchanging dynamics of projects (Conforto, Salum, Amaral, da Silva, \& Magnanini de Almeida, 2014). Innovative projects involve the invention of new services or products. Software development endeavors are affiliated to creative projects, as well. Currently software as well as many other industry sectors are confronting similar issues, such as fast changing dynamics, and challenges when managing innovative projects (Conforto et al., 2014; Gustavsson, 2016). To overcome this situation, a heterogeneous number of organizations are adopting agile methodologies into project management. Constant change characterizes organizations' environments due to changing business requirements, customer needs, and technology advancements (Baham, Hirschheim, Calderon, \& Kisekka, 2017), Agile methodologies had been embraced in the software industry (VersionOne, 2018). Software companies, such as Amazon, Spotify, Zappos, Netflix, and Google are using agile methodologies to manage innovative projects (Birkinshaw, 2018). Besides the software industry, other sectors and industries are integrating agile methods in project management, as software development for those industries is required to incorporate technological innovations. Education is benefiting from agile methodologies, as Tsai, Chen, \& Chen (2018) pointed out. The Toyota Production System from the automobile industry is depleting agile methods (Repenning, Kieffer, \& Repenning, 2018; Baham et al., 2017; Mirzaei, \& Mabin, 2017; Stoica, Ghilic-Micu, Mircea, \& Uscatu, 2016). Internet and mobile banking were early agile methodologies adopters (Birkinshaw, 2018). Agile methods have been used to develop government policies (Mirzaei, \& Mabin, 2017). It is essential that non-software companies transform into more agile and flexible ways of managing projects, as software organizations do, to acquire and develop such new capabilities to be more competitive in the future (Kettunen, \& Laanti, 2017).

\section{Justification for the study}

It is not clear which role project management research has played in the development of the agile academic discourse (Lechler, \& Yang, 2017). More and more companies use agile methods, notwithstanding organizational culture continues to be the challenge for its implementation (VersionOne, 2018). Agile methods are more suitable for liberal organizations, but a comparison of agile methodologies and project characteristics is still needed (Rajagopalan, \& Mathew, 2016). Different agile methods can be studied further to discover its applicability in projects 
(Mirzaei, \& Mabin, 2017). Since there are an increasing number of agile advocates, it is vital to find the right response to these issues. Research in the area can help to answer these uncertainties. In short, agile methodologies must be assessed to improve its implementation in project management continually. This study focuses precisely on the assessment of agile methodologies in project management by analyzing different considerations found in the literature. The analysis supplies enough evidence to synthesize data creating an improved technique that incorporates the best of each of the agile methodologies used today in project management.

An optimized agile technique (OAT) is proposed to manage projects in software and non-software industries efficiently. OAT is a strategy to give direction on how to implement the best of agile methodologies to the management of projects, especially those related to innovation. A wide range of industries can benefit from OAT, as it helps taking advantage of agile methods while overcoming all challenges that may arise. OAT may even allow more organizations to adopt agile methods since it is an enhanced practice. The article presents a background on agile methodologies; the research methodology employed and findings on recent research. OAT insights are discussed and conclusions made from the findings. Lastly, the limitations of the study are presented, as well as directions for future research.

\section{BACKGROUND}

\section{Agile methodologies}

Project management evolves in a dynamic atmosphere. Agile methodologies provide ways to respond in that everchanging environment. Given the VersionOne (2018) report, there are four areas that agile methods are helping organizations to grow. First, agile methodologies provide guidelines to manage priorities. Second, those methods support the alignment between business and the Information Technology (IT) department. Third, the agile concept promotes faster software delivery to the customer, who is the system user. Lastly, agile methods foster team increased productivity. Many agile methodologies had emerged lately, which must be used wisely by the team in the project (Mihalache, 2017). The first agile methodology concept, which materialized in 2001, consisted of twelve principles. Some of the most significant statement are: i) establishing a highly collaborative team; ii) working autonomously by continually evaluating performance in iterative, incremental design and development, and iii) adjusting efforts to become more effective in delivering the scope, which can change, even in later stages of the project, especially in software development (Henriques, \& Tanner, 2017). Agile methods consist of focusing on the project's customer, allowing autonomy to project team members (Birkinshaw, 2018). These methods focus on delivering value at a constant time, cost, and quality project frame (Kisielnicki, \& Misiak, 2016). Agility is associated to give a quick response to changing environments when managing projects; which is common in software development projects (Erickson, Lyytenen, \& Siau, 2005). There are many agile methods or manifestations to respond to the different demands a project may have (Repenning, Kieffer, \& Repenning, 2018). There are many agile methodologies, such as Scrum, XP, Pair programming, and iterative development (Henriques, \& Tanner, 2017). In this article, we will describe Scrum, Kanban, Axiomatic Design, Adapt, Extreme Programming, Crystal, Agile Software Process, and Pragmatic Programming, as being the most notorious in our review.

\section{Description of each agile methdology}

Agile Manifesto, an agile methodology, has been used in the project management area for the last two decades. Gustavsson (2016) explained Manifesto emphasizes customer approval. Scrum, based on Manifesto, is the most commonly used approach (Stoica et al., 2016); (Bhoola, \& Mallik, 2014). Scrum is a method to manage complex projects while supporting creativity. Scrum focus on transparency, inspection, verification, and adaptation. Scrum combines processes and techniques to construct the solution (Stoica et al., 2016). Its team is composed of a Scrum master, the product owner, and the development team (Weber, Förster, Stäbler, \& Paetzold, 2017). The Scrum master facilitates the productivity of the team. The product owner is in charge of prioritizing work performed by the team. The product owner represents the stakeholders and the customers. The development team works independently. The project advances in iterations or short cycles, called Sprints (Makoto-Higuchi, \& Noboru-Nakano, 2017). On each sprint, it is necessary to evaluate the plan for delivering the product (Weber et al., 2017). The iteration of steps throughout the development process helps controlling project risks. The project concludes after many sprints or iterations. Kanban focuses on improving ongoing activities aiming to enhance operations continuously. This technique requires excellent communication efforts from the team, who must be proactive anticipating problems (Stoica et al., 2016). Scrumban is a hybrid between Scrum and Kanban which emphasizes the working crew 
should be comfortable with the project methodology while implementing the changes to product requirements, and the variations of stakeholder interests (Stoica et al., 2016). Axiomatic Design fosters the decomposition of a design task from the highest level to the most abstract level (Weber et al., 2017). Axiomatic Design offers lean development process, especially convenient for large organizations and maps the solutions between the customer, functional, physical and process requirements (Weber et al., 2018). Adapt, proposed by Weber et al. (2017), is based on Scrum and Axiomatic Design and fosters adjustments in the procedures to the precise necessities of the development team. Adapt promotes flexibility and embracing the opportunities new circumstances may bring (Weber et al., 2017). Extreme Programming (XP) is a customer-oriented technique that brings customer participation, while not addressing management requirements. It operates in short iterations and provides releases of work in short periods of time to continually refine its output (Rajagopalan, \& Mathew, 2016). Crystal is flexible enough to allow the tailoring of the business rule of thumbs (Rajagopalan, \& Mathew, 2016). Agile Software Process (ASP) emphasizes faster development, even with unstable requirements (Rajagopalan, \& Mathew, 2016). Pragmatic programming (PP) uses a realistic approach to develop solutions to a given problem (Rajagopalan, \& Mathew, 2016).

\section{RESEARCH METHODOLOGY}

Qualitative and quantitative research was used to develop a systematic literature review to formulate a new concept or idea to be named OAT, which is the construct of interest. The variables used were authors last names, publication year, agile method name, agile method advantage, and agile method challenge. This study is qualitative as it is a review of different articles containing information about agile project management. For each literature piece, we listed its agile method benefits and difficulties. The study becomes quantitative when we finished noting the advantages and the challenges for agile methods and started constructing the systematic approach, using meta-analysis, to propose OAT. There is plenty of information about agile methods for project management. The "peer-reviewed" articles for this study were found in the University Library System, specifically in the Business Source Ultimate database. The key words for searching the articles were "agile methodologies" and "project management" within the subject terms.

\section{Inclusion criteria}

To provide enough research material and to ensure current literature, articles published between January 2017, and April 2018, were selected. Another criterion was that the reviewed material presented a study of agile project management and that the discussion or conclusion sections of the articles chosen had the variables to be looked up. Those specific variables were agile method advantage and agile method challenge.

\section{Exclusion criteria}

Articles published before January 2017 were not selected to avoid the overwhelming task of managing significant numbers of data. Another exclusion criterion was that the literature item did not present a study about agile project management. The advantages and challenges must be listed in either the conclusion or the discussion section; otherwise, they were rejected.

\section{Research objectives}

1. To evaluate agile methodologies from different studies, and

2. To synthesize the valued agile methodologies material into one study

\section{Proposition}

The proposition is the primary focus of this study. The proposition is:

- From the synthesis of previous studies, this research provides an improved technique, OAT, that incorporates the best of each of the agile methodologies used today integrating it to project management.

\section{Research tools}

The research tool to classify the advantages and challenges from the articles was Microsoft Access ${ }^{\circledR}$ (2016). Figure 1 shows the query, or collection of tables, used to classify the agile advantages and challenges from the articles. We also used Microsoft Excel® (2016) to construct the charts. 


\section{Meta-analysis}

Although many fields, such as Medicine, Education, and Psychology (Hwang, 1996), commonly utilize metaanalysis methodology, Project Management and Information Systems may not use it frequently. This study is one of the few ones that use meta-analysis to declare a research proposition, in this case, OAT. It is worth to briefly explaining the meta-analysis methodology. As Hwang (1996) suggested, meta-analysis can be used whenever there is a need to integrate the findings of past studies. Our research, indeed, is about the synthesis of different studies to find out what must be the focus when using agile techniques. That focus is the proposition we made, which is what we called OAT.

In overall, our research complied with the meta-analysis, except for a variation in the effect size suggested by Hunter, Schmidt, and Jackson (1982). The authors explained the effect size assumes to use quantitative data from different studies. Statistical analysis can be performed with that quantitative data. In our research, however, we had to use what was available, which was qualitative data, instead of quantitative data. Hunter, Schmidt, and Jackson (1982) did not specify what to do when qualitative data is the only data found for research while emphasizing on the fact that meta-analysis involves some degree of arbitrarily.

Hwang (1996) explained data availability constitutes an obstacle in Information Systems research and related fields when using meta-analysis. Therefore, we had to adopt what the authors suggested to reach our goal, which was the OAT proposition, as it presented in Table 1. Our adoption of meta-analysis consisted of managing qualitative data by collecting all the advantages and disadvantages of each agile method found in the different studies. Following Hwang (1996), our moderator variable is the OAT proposition, and the mediator variables are the advantages and disadvantages. We, then, counted the total number of advantages and disadvantages per study and plotted a forest chart, shown in Figures 2 and 3, as suggested by Crowther, and Lim (2010). Our conclusions and recommendations arose from those plots. As Hwang, Windsor, and Pryor (2000) suggested, we do not recommend making generalizations to the population, instead to consider our study as one that contributes to understanding better the agile techniques phenomenon.

\section{FINDINGS}

Nineteen articles were selected. One of them had to be eliminated since its focus was only on software development, but not about agile methodology. The eliminated article was Kudaravalli, Faraj, \& Johnson (2017). The revised number of articles included for this study then were 18, which included: Baham et al., 2017; Bider, \& Perjons, 2017; Birkinshaw, 2018; Dovleac, \& Ionică, 2017; Henriques, \& Tanner, 2017; Kettunen, \& Laanti, 2017; Kim, Park, \& Katalwar, 2017; Lechler, \& Yang, 2017; Makoto-Higuchi, \& Noboru-Nakano, 2017; Manole, \& Avramescu, 2017; Mihalache, 2017; Mirzaei, \& Mabin, 2017; Nkukwana, \& Terblanche, 2017; Repenning, Kieffer, \& Repenning, 2018; Tsai, Chen, \& Chen, 2018; Varajão, 2018; Weber et al., 2017 and Wolfgang, 2017. After organizing data in Microsoft Access ${ }^{\circledR}$, from those 18 articles, we found 96 advantages for using agile methodologies in project management, whereas we found 74 challenges.

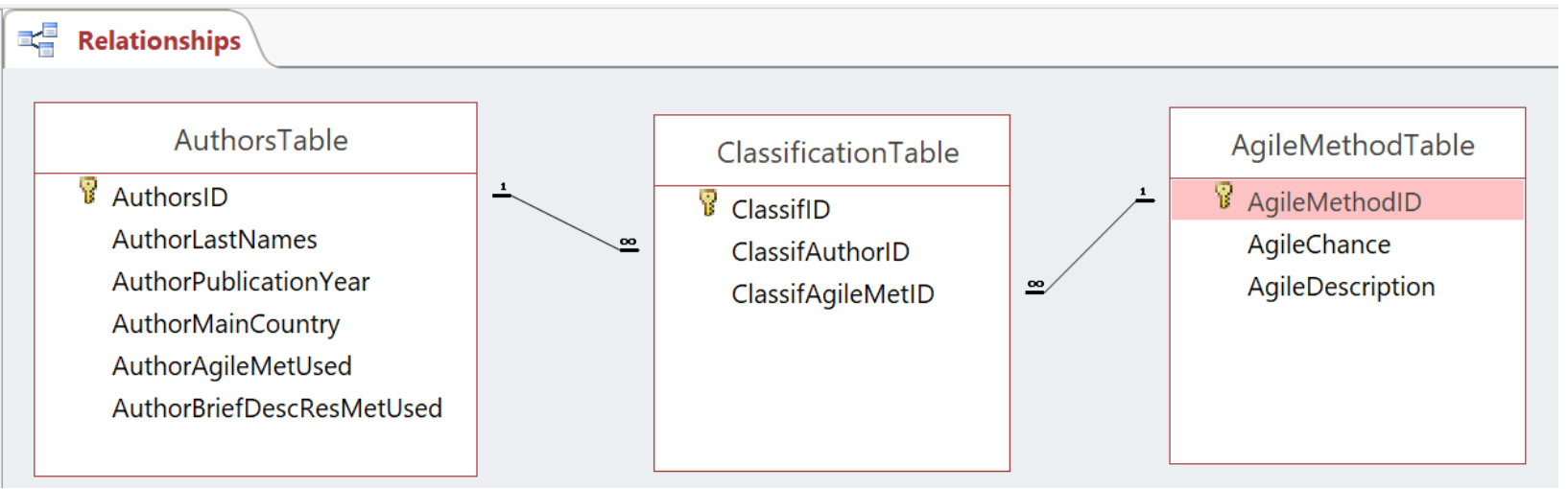

Figure 1. Microsoft Access ${ }^{\circledR}$ Query to classify data for the study 


\section{Issues in Information Systems}

Volume 19, Issue 2, pp. 119-131, 2018

Table 1 shows the list of articles, and the total number of advantages and challenges found. This table shows six columns. The first column is the identification number, and the second column is the list of articles selected for the study, identified by its authors and the year of publication. The third and fourth columns show the advantages and challenges respectively found in each article. The number of challenges is shown in negative figures since those are issues to be overcome, as well as to be able to construct the chart. The fifth column represents the status. If the article had only advantages, nor any challenges, then it is considered to be an outlier. An outlier article refers to one whose authors did not present any challenges. If the article has the same number of advantages and challenges, then it is considered to be neutral. Neutralities and outliers were rejected since those go beyond the purpose of the study. If the status column is empty, then that article has a good standing to be further analyzed. There are three neutral articles and three articles that prove to be outliers. The neutral articles were Henriques, \& Tanner, 2017, Lechler, \& Yang, 2017, and Repenning, Kieffer, \& Repenning, 2018. The outlier articles were Bider, \& Perjons, 2017, Makoto-Higuchi, \& Noboru-Nakano, 2017, and Wolfgang, 2017. That led us to 12 articles, having 77 advantages and 65 challenges to continue the study.

Figure 2 shows the preliminary meta-analysis chart for the selected literature. The initial meta-analysis combined data from the different articles and created one pooled estimate of results. The goal in this meta-analysis study was to find articles that were consistent, identifying a common effect. That consistency allowed us to highlight a common ground to develop a new concept or theory. The x-axis goes from -80 to 100 because the number of challenges found in the 12 articles was 65 , and the number of advantages was 77 . Challenges were represented in negative numbers to be able to construct the meta-analysis chart. The smallest the negative number, the more challenges there were. The largest the positive number, the more advantages there were to implement agile methods in project management. The y-axis represented each article included in the study. The authors and the publication year identified the 12 articles in the graph. There was a $13^{\text {th }}$ element in the axis shows the Grand Total for all articles. Each one had a straight line that includes three points. The far left dot represented the number of challenges found in that article. The middle dot was the average for the challenges and the advantages. The far right dot depicted the total number of advantages in that article. There were 12 three-dot straight lines since there were 12 articles included in the initial meta-analysis chart. The $13^{\text {th }}$ element is the Grand Total showing the longest straight line since it incorporates all article aggregates. Its far left dot represented a total of 65 challenges found in all the articles included in the chart. Its faraway right dot signified a total of 77 advantages found. Its center was the average; its size represented as a diamond. The diamond place implied there was more advantages found that there were challenges. The dark line in the center of the graph denoted zero (0). This line was helpful to have a reference to the positive and negative numbers of the dotted straight lines. The two vertical lines that run parallel to the vertical dark centerline were drawn to identify consistency among the articles. All articles, which three-dot straight line fell into those two vertical lines were further analyzed. Those chosen articles were (Tsai, Chen, \& Chen, 2018; Manole, \& Avramescu, 2017; and Dovleac, \& Ionică, 2017). Those three articles included six advantages of using agile methodologies in project management and nine challenges. Figure 3 shows the list of articles selected for the study. Those three articles fell into the consistency lines. The first column identifies the articles picked, which is the authors' last names, and its publication year. The second column has the name of the agile methodology. The AgileChance column shows if an advantage or if a challenge was found. The AgileDescription column gives details of the agile method that was located in the article. 
Table 1. List of articles with its total of advantages and challenges, its average, and its status for the study

\begin{tabular}{|l|c|c|c|c|}
\hline AuthorLastNames & Advantages & Challenges & Average & Status \\
\hline 1 (Baham, Hirschheim, Calderon, \& Kisekka, 2017) & 11 & -6 & 2.5 & \\
\hline 2 (Bider, \& Perjons, 2017) & 2 & 0 & 1 & outlier \\
\hline (Birkinshaw, 2018) & 4 & -7 & -1.5 & \\
\hline 4 (Dovleac, \& lonică, 2017) & 2 & -4 & -1 & \\
\hline 5 (Henriques, \& Tanner, 2017) & 2 & -2 & 0 & neutral \\
\hline (Kettunen, \& Laanti, 2017) & 26 & -21 & 2.5 & \\
\hline 7 (Kim, Park, \& Katalwar, 2017) & 7 & -2 & 2.5 & \\
\hline (Lechler, \& Yang, 2017) & 4 & -4 & 0 & neutral \\
\hline 9 (Makoto-Higuchi, \& Noboru-Nakano, 2017) & 4 & 0 & 2 & outlier \\
\hline 10 (Manole, \& Avramescu, 2017) & 1 & -3 & -1 & \\
\hline 11 (Mihalache, 2017) & 5 & -1 & 2 & \\
\hline 12 (Mirzaei, \& Mabin, 2017) & 5 & -3 & 1 & \\
\hline 13 (Nkukwana, \& Terblanche, 2017) & 1 & -6 & -2.5 & \\
\hline 14 (Repenning, Kieffer, \& Repenning, 2018) & 4 & -4 & 0 & neutral \\
\hline 15 (Tsai, Chen, \& Chen, 2018) & 3 & -2 & 0.5 & \\
\hline 16 (Varajão, 2018) & 6 & -7 & -0.5 & \\
\hline 17 (Weber, Förster, Stäbler, \& Paetzold, 2017) & 6 & -2 & 2 & \\
\hline 18 (Wolfgang, 2017) & 3 & 0 & 1.5 & outlier \\
\hline 19 Grand total & 96 & -74 & 11 & \\
\hline
\end{tabular}

Figure 4 shows the meta-analysis chart containing the synthesized article data, as it was the goal find consistency among the articles to be able to identify common ground to develop a new concept or theory, OAT for the sake of this study. The $\mathrm{x}$-axis goes from -10 to 10 because the number of challenges found in the three articles was 9 , and the number of advantages was 6 . Challenges were represented in negative numbers to be able to construct the metaanalysis chart. The smallest the number, the more challenges there were to achieve agile methods in project management. The larger the number, the more advantages there were to implement agile practices in project management. The y-axis represented each article included in the synthesis. The authors and the publication year identified each article. There was a fourth element in the axis showing the Grand Total. Each article had a straight line that includes three geometric figures. The far left geometric figure represented the number of challenges found in that article. The central geometric picture was the average of challenges and the number of advantages. The far right geometric symbol represented the number of advantages found in that article. There were three straight lines since there were three articles included in the meta-analysis chart. The fourth element that showed the Grand Total for all three articles had the longest straight line, including three diamonds. Its far left diamond represented a total of 9 challenges found in all the articles included in the chart. Its far right diamond outlined a total of six advantages found. Its center is a larger diamond, which was the average. The diamond place implied there were more challenges encountered than there were advantages. The dark line in the center of the graph represented zero (0). This line was the reference between the positive and negative numbers. Moreover, Figure 4 is the synthesis of what Figure 2 presented. Figure 4 has the same two vertical lines that run parallel to the dark vertical centerline were drawn to highlight the consistency among the articles from Figure 2. Figure 4 illustrates all articles, which straight-line fell into those two vertical lines were selected because their agile studies showed accuracy, uniformity in its results. The chosen articles were Tsai, Chen, \& Chen, 2018; Manole, \& Avramescu, 2017; and Dovleac, \& Ionică, 2017. 


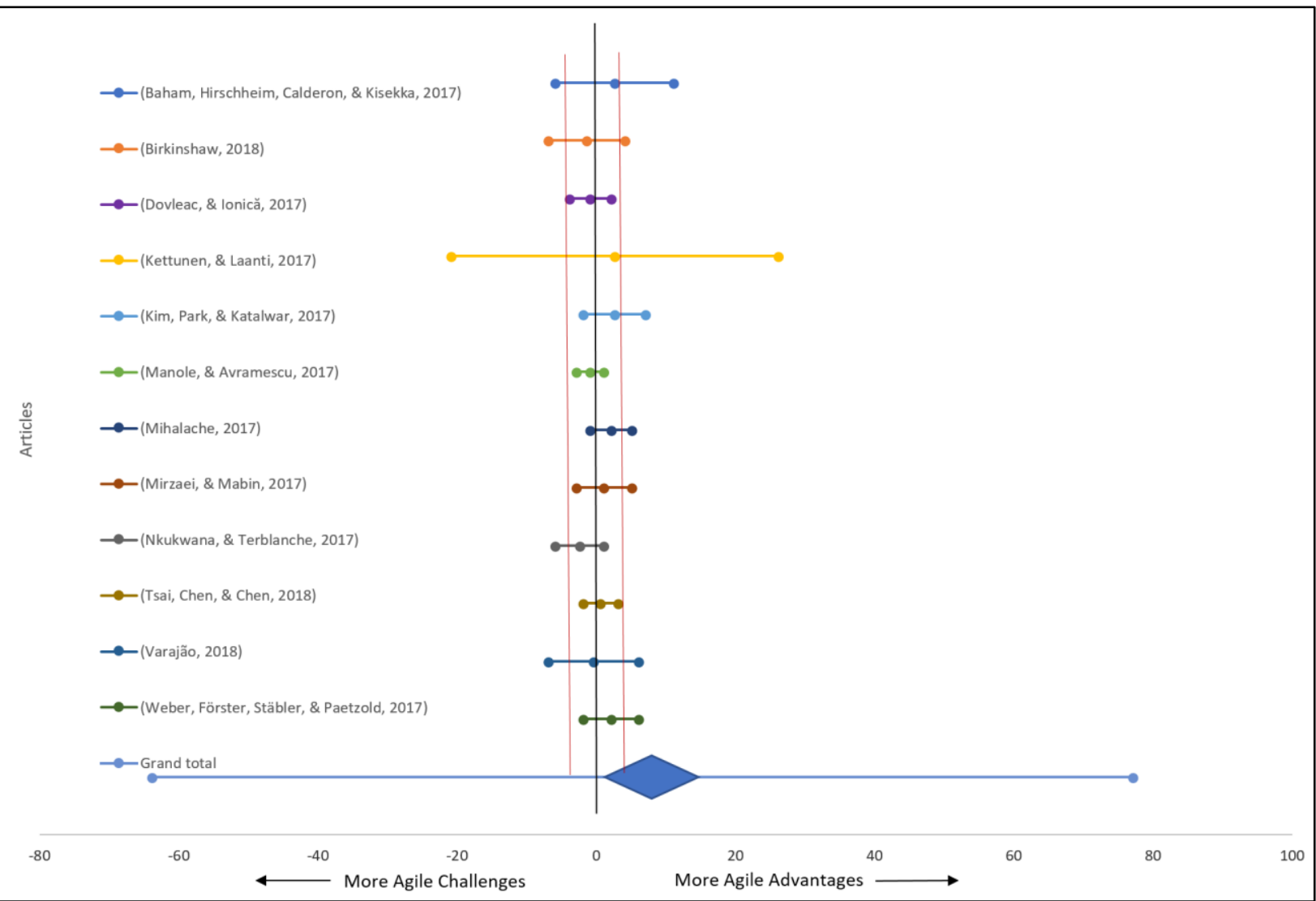

Figure 2. The preliminary meta-analysis chart

\begin{tabular}{|c|c|c|}
\hline AuthorLastNames & AuthorAgileMetUsed & AgileChance \\
\hline (Dovleac, \& lonică, 2017) & Plan-Do-Check- Act (PDCA) cycle & e Advantage \\
\hline (Dovleac, \& lonică, 2017) & Plan-Do-Check- Act (PDCA) cycle & e Challenge \\
\hline (Dovleac, \& lonică, 2017) & Plan-Do-Check- Act (PDCA) cycle & e Challenge \\
\hline (Dovleac, \& lonică, 2017) & Plan-Do-Check- Act (PDCA) cycle & e Advantage \\
\hline (Dovleac, \& lonică, 2017) & Plan-Do-Check- Act (PDCA) cycle & e Challenge \\
\hline (Dovleac, \& lonică, 2017) & Plan-Do-Check- Act (PDCA) cycle & e Challenge \\
\hline (Manole, \& Avramescu, 2017) & agile methodology tools & Advantage \\
\hline (Manole, \& Avramescu, 2017) & agile methodology tools & Challenge \\
\hline (Manole, \& Avramescu, 2017) & agile methodology tools & Challenge \\
\hline (Manole, \& Avramescu, 2017) & agile methodology tools & Challenge \\
\hline (Tsai, Chen, \& Chen, 2018) & Snowman approach & Challenge \\
\hline (Tsai, Chen, \& Chen, 2018) & Snowman approach & Advantage \\
\hline (Tsai, Chen, \& Chen, 2018) & Snowman approach & Challenge \\
\hline (Tsai, Chen, \& Chen, 2018) & Snowman approach & Advantage \\
\hline (Tsai, Chen, \& Chen, 2018) & Snowman approach & Advantage \\
\hline
\end{tabular}

Figure 3. List of articles selected for the study 


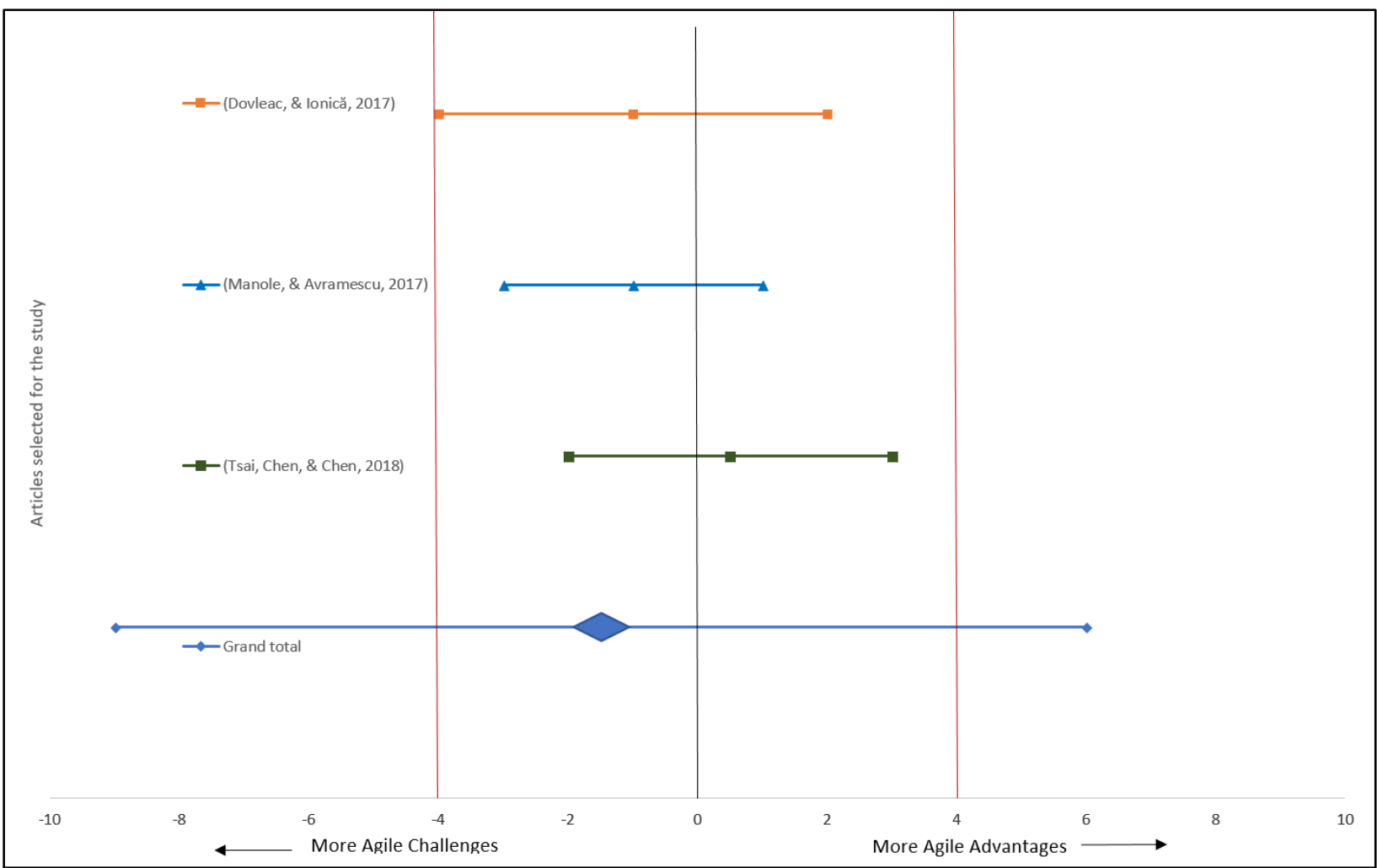

Figure 4. The meta-analysis chart

\section{OAT INSIGHTS AND DISCUSSION}

This study postulates new insights that significantly contribute to agile project management knowledge. It extends the existing theory by providing a conceptualization of agile methodologies and its implementation to project management. First, a database stored and organized all the advantages, and challenges from the systematic review of the articles. Then, by conducting a meta-analysis, the study combined number of advantages and challenges found in all articles, arranged data so that articles with a consistent number of advantages and challenges could be identified and picked. The picked articles demonstrated consistency among the rest. Those articles selected were (Dovleac, \& Ionică, 2017; Manole, \& Avramescu, 2017; and Tsai, Chen, \& Chen, 2018). Its advantages and challenges were conceptualized into an improved agile method, called the optimized agile technique (OAT). It is a synthesis or the essence of what agile project management must emphasize to be successful. This study is not a summary of agile methods; instead is based on consistent agile project management advantages and challenges to formulate its new premise. OAT, the proposition, is an improved procedure for implementing agile methods in project management. The background section of this article discussed the different agile methods that exist today. OAT is a practical guide to successfully implementing those agile methods into project management.

\section{Research objective 1: To evaluate agile methodologies from different studies}

After reviewing 19 articles, yet the research ended up with three of those. The narrowing down started by choosing articles whose studies were concerning agile project management. From that, we identified each article with its authors' last name, and its publication year. Then, we wrote the name of the agile method being studied in the article. Further, we read each one looking for the advantages, and challenges of implementing agile methods in project management, which were mentioned in the discussion or conclusion sections. Advantages referred to the benefits of adopting agile methods into projects. Challenges referred to the difficulties that were confronted by implementing the agile method. The advantages and challenges were organized using a database tool, Microsoft Access ${ }^{\circledR}$. According to the number of advantages and challenges found, we could remove some articles considered either neutral or outliers. Neutral articles stated the same total number of advantages and the same total number of challenges. 


\section{Issues in Information Systems}

Volume 19, Issue 2, pp. 119-131, 2018

Outlier articles were those that presented advantages solely. Twelve articles were used to construct a preliminary meta-analysis chart showed in Figure 2. The chart allowed us to find out consistencies among the different articles. We selected those articles with a total number of advantages, and a total number of challenges fell into similarly. Any articles those total numbers of advantages, and challenges fell out of a predetermined consistent area were eliminated from this study. Discarded articles presented a lot of variation, which may arise from a diversified number of reasons that required in-depth analysis that goes beyond the scope of this study. We finalized with three articles, which were Dovleac, \& Ionică, 2017; Manole, \& Avramescu, 2017; and Tsai, Chen, \& Chen, 2018 from the preliminary meta-analysis.

\section{Research objective 2: To synthetize the evaluated material into one study}

The meta-analysis chart showed in Figure 4, including the three articles, which were Dovleac, \& Ionică, 2017; Manole, \& Avramescu, 2017; and Tsai, Chen, \& Chen, 2018 from the preliminary meta-analysis. These three articles showed consistency among its studies. That uniformity had a powerful effect on our research since its total number of advantages, and challenges were accurate within each other. The formulation of our OAT proposition is the synthesis of these three articles' advantages and challenges. It is important to explain each of the articles' contribution. The first article (Dovleac, \& Ionică, 2017) discussed Plan-Do-Check-Act (PDCA) cycle, which was a variation of agile methods to ensure quality management while creating projects, especially startups. The advantages presented in the article were a high level of feedback from customers, and flexible enough to promote creativity. The estimation of proper time to complete tasks is difficult was the first challenge found. The second challenge found was that quality must be monitored at all stages of the project while using agile methods. The third challenge was the standards must be in place from the beginning stages of the project. The fourth challenge found was the complexity of not having a well-determined quality standard from the beginning to the ending of the project. The second article (Manole, \& Avramescu, 2017) discussed the evaluation of agile method tools; which are Atlassian JIRA, Taiga, Version One, Assembla, and Asana. The advantage was that there are a wide variety of agile meth-od tools improving project management significantly. The challenges were choosing the most appropriate tool for the allocation of values results for the project, the knowing the way those agile tools help improving productivity, and, even though the use of agile tools, effective project management still relies on regular communication. The third article (Tsai, Chen, \& Chen, 2018) discussed the Snowman approach, based on agile methods. It institutionalized team communication through holding short time meetings. The advantages were better software development documentation, better evidence of communication and improved overall communication. The challenges found were the prioritization of tasks is fundamental when supervising employees, and the teams are not always comfortable with short meetings. The preliminary meta-analysis suggested that there are more advantages than challenges when implementing agile methods into projects, as the Figure 2 centered diamond Grand Total showed. Whereas, the meta-analysis, which looked for consistency among articles, suggested that there are more challenges than advantages when implementing agile methods into the management of projects, as the Figure 4 centered diamond Grand Total showed.

\section{Proposition}

OAT is a strategy to adopt agile methodologies for effective project management. It consists of:

1. The selection of the right agile method tool (Manole, \& Avramescu, 2017) to manage projects efficiently;

2. The constant authenticating quality standards (Dovleac, \& Ionică, 2017) to add value to customer expectations, and

3. The promotion of an open and frequent communication channel among working teams (Tsai, Chen, \& Chen, 2018) to conduct project activities harmoniously.

\section{Recommendations}

According to OAT, when adopting agile methods for project management, it is essential: i) To wisely select the agile method tool for the efficacy of the project (Manole, \& Avramescu, 2017); ii) To authenticate quality management in projects (Dovleac, \& Ionică, 2017); and iii) To establish a communication open enough for holding frequent short time meetings among project teams (Tsai, Chen, \& Chen, 2018). There are areas of attention when implementing the OAT proposition: - Choose the most appropriate agile method tool among the different kinds that exist (Manole, \& Avramescu, 2017), taking the most benefit those can bring to the management of projects. Some of the agile tools to consider are MS Project 2016, Atlassian JIRA, Taiga, Version One, Assembla, and Asana. • Although agile methods promote a high level of customer response, and enough freedom for creation (Dovleac, \& Ionică, 2017), proper quality standards must be in place from the project initiation to the lessons learned phases of the project to ensure value added to customer demands. - Mainly, setting up appropriate communication among working 
teams is key to project success. Meetings must be and often, and short (Tsai, Chen, \& Chen, 2018). Prioritization of tasks must be the focus of the team conversations while creating documentation as future evidence.

\section{CONCLUSIONS}

Agile methodologies can be tailored to project management (Mirzaei, \& Mabin, 2017). Agile methods are still underrepresented in the project management context, leading an opportunity to research that area (Lechler, \& Yang, 2017). Even though this underrepresentation, agile methodologies to improve management in innovative projects are benefiting a wide range of industries, besides software industry. (Conforto et al., 2014, Birkinshaw, 2018, Gustavsson, 2016, Baham et al., 2017, Garnett, Jones, \& Murray, 1998, Aziz, 2012, Ramasubbu, Bharadwaj, \& Tayi, 2015, Stoica et at., 2016, and Mirzaei, \& Mabin, 2017). Optimized agile technique (OAT) is the proposition of this study, which is a pragmatic model for adequately implementing the agile project management in software and nonsoftware industries. OAT is a new strategy to achieve the best of agile methodologies to the management of projects. OAT requires three main aspects when implementing agile project management:

1. Wisely selecting select the agile method tool for the efficacy of the project (Manole, \& Avramescu, 2017);

2. Authenticating quality management in projects (Dovleac, \& Ionică, 2017), and

3. Establishing a communication open enough for holding frequent short time meetings among project teams (Tsai, Chen, \& Chen, 2018).

\section{Implications}

OAT is a pragmatic view to assess and adopt agile project management from the vast amounts of information in the area. OAT responded to the Lechler, \& Yang (2017) suggestion of the need for more conceptual research and the development of a theoretical perspective on agile. It is worth noting that the project life cycles (PMBOK® Guide, 2018) can be aligned with agile methods. OAT proposition can be an initial step in the incursion of agile projects into the project life cycle since it is concise and easy to understand. OAT can be used in managing projects, especially those related to innovation in different of industries, including software.

\section{Limitations of the study}

Since OAT is in its conceptual stage, generalizations should be done with caution. Nevertheless, OAT is a useful resource for agile project management assessment. This study only considered published articles from on the Business Source Ultimate university library database, as The Web of Science was not available at the university's library at the time of this research. Notwithstanding, the study managed enough information to meet its purpose. Moreover, this study classified agile methodology data into advantages and challenges to develop OAT. Its two authors did that classification independently, as Crocetti (2016) suggested. There were no discrepancies found among the two authors analysis. But, if discrepancies in the analysis would have arrived, then it may have been a limitation. The use of a third author may have been helpful to solve for such discrepancies.

Hwang, Windson, and Pryor (2000) suggested that the validity of a meta-analysis might be an issue due to the ample variation of study characteristics. Consequently, it is not advised to make generalizations from the sample to the population, which may constitute a limitation of the study. Nonetheless, the meta-analysis is useful to understand better an area of study, and that is what our research did.

\section{Directions for future research}

OAT is in its conceptual phase. Future work can test the effectiveness of project management when applying OAT. Also, it would be interesting to compare OAT project management in different industries. Examining OAT adoption in project management may bring new horizons to organizations, as well as OAT can become generalizable to diverse companies. As Hwang (1996) suggested, the purpose of utilizing meta-analysis was mainly to provide direction for future research, rather than to settle for generalization. 


\section{REFERENCES}

Aziz, B. (2012). Improving Project Management with Lean thinking? Retrieved from http://liu.divaportal.org/smash/get/diva2:504715/FULLTEXT01.pdf

Baham, C., Hirschheim, R., Calderon, A. A., \& Kisekka, V. (2017). An agile methodology for the disaster recovery of Information Systems under catastrophic scenarios. Journal of Management Information Systems, 34(3), 633-663. https://doi.org/10.1080/07421222.2017.1372996

Bhoola, V., \& Mallik, D. (2014). Determinants of Agile Practices : A Gini index approach * Agile Methods : The Scrum Way. Journal of Management, 11(2).

Bider, I., \& Perjons, E. (2017). Towards a business process modeling technique for agile development of case management systems. Complex Systems Informatics and Modeling Quarterly, (13), 73-113. https://doi.org/https://doi.org/10.7250/csimq.2017-13.05

Birkinshaw, J. (2018). What To expect from agile. MIT Sloan Management Review, 39-42. https://doi.org/10.1142/S201000781100019X

Conforto, E. C., Salum, F., Amaral, D. C., da Silva, S. L., \& Magnanini de Almeida, L. F. (2014). Can agile Project Management be adopted by industries other than software development. Project Management Journal, 45(3), 21-34.

Crocetti, E. (2016). Systematic Reviews With Meta-Analysis: Why, When, and How? Emerging Adulthood, 4(1), 318.

Crowther, M., \& Lim, W. (2010). Systematic review and meta-analysis methodology. Blood, 116(17), 3140-3146.

Dovleac, R., \& Ionică, A. (2017). Quality management techniques embedded in agile project development. MATEC Web of Conferences, 121, 05003 (2017), 121, 5003. https://doi.org/10.1051/matecconf/201712105003

Erickson, J., Lyytinen, K., \& Siau, K. (2005). Agile modeling, agile software development, and extreme programming. Journal of Database Management, 16(4), 88-100. https://doi.org/10.4018/jdm.2005100105

Garnett, N., Jones, D. T., \& Murray, S. (1998). Strategic application of Lean thinking. In Proc. 8th Ann. Conf. of the Int'l. Group for Lean Construction'98. Guaruja, Brazil.

Gustavsson, T. (2016). Benefits of agile project management in a non-software development context - A literature review. In Project Management Development - Practice and Perspectives: Fifth International Scientific Conference on Project Management in the Baltic Countries April 14-15, Riga, University of Latvia (pp. $67-82)$.

Henriques, V., \& Tanner, M. (2017). A systematic literature review of agile and maturity model research. Interdisciplinary Journal of Information, Knowledge, and Management, 12, 53-73. https://doi.org/10.5121/ijsea.2012.3202

Hunter, J. E., Schmidt, F. L., \& Jackson, G. B. (1982). Meta-Analysis : Cumulating Research Findings across Studies. Sage Publication: Beverly Hills. Retrieved from http://www.jstor.org/stable/1175263

Hwang, M. I. (1996). The use of meta-analysis in MIS research: Promises and problems. Data Base for Advances in Information Systems, 27(3), 35-48. https://doi.org/10.1145/264417.264433

Hwang, M. I., Windsor, J. C., \& Pryor, A. (2000). Building a knowledge base for MIS research: A meta-analysis of a systems success model. Information Resources Management Journal, 13(2), 26-32. 


\section{Issues in Information Systems}

Volume 19, Issue 2, pp. 119-131, 2018

Johnson, J. (2018). CHAOS Report: Decision Latency Theory: It Is All About the Interval (Second Edition). The Standish Group. Retrieved from http://www.lulu.com/shop/http://www.lulu.com/shop/jamesjohnson/chaos-report-decision-latency-theory-it-is-all-about-the-interval/paperback/product-23596093.html

Kettunen, P., \& Laanti, M. (2017). Future software organizations - agile goals and roles. European Journal of Futures Research, 5(16). https://doi.org/10.1007/s40309-017-0123-7

Kim, M., Park, Y., \& Kotalwar, R. (2017). Robust and agile system against fault and anomaly traffic in software defined networks. Applied Sciences, 7(266), 2-17. https://doi.org/10.3390/app7030266

Kisielnicki, J., \& Misiak, A. M. (2016). Effectiveness of agile implementation methods in business intelligence projects from an end-user perspective. Informing Science: The International Journal of an Emerging Transdiscipline, 19, 161-172. https://doi.org/10.1515/fman-2017-0021

Kudaravalli, S., Faraj, S., \& Johnson, S. L. (2017). A configurational approach to coordinating expertise in software development teams. MIS Quartery, 41(1), 43-64.

Lechler, T. G., \& Yang, S. (2017). Exploring the role of Project Management in the development of the academic agile software discourse: A bibliometric analysis. Project Management Journal, 48(1), 3-18.

Makoto-Higuchi, M., \& Noboru-Nakano, D. (2017). Agile Design: a combined model based on design thinking and agile methodologies for digital games projects. Revista de Gestão E Projetos -GeP, 8(2), 109-127. https://doi.org/10.5585/gep.v8i2

Manole, M., \& Avramescu, M. (2017). Comparative analysis of agile project management tools. Economy Informatics, 17(1), 25-31.

Mihalache, A. (2017). Project Management tools for agile teams. Informatica Economica, 21(4), 85-93. https://doi.org/10.12948/issn14531305/21.4.2017.07

Mirzaei, M., \& Mabin, V. (2017). Agile Project Management and Public Policy Development Projects : A case study from New Zealand. New Zealand Journal of Applied Business Research, 15(1), 59-76.

Nkukwana, S., \& Terblanche, N. H. D. (2017). Between a rock and a hard place: Management and implementation teams' expectations of project managers in an agile information systems delivery environment. South Africa Journal of Information Management, 19(1), 1-11. https://doi.org/10.4102/sajim.v19i1.806

Project Management Institute. (2018). A Guide to the Project Management Body of Knowledge (PMBOK® Guide). (6th ed.). Project Management Institute. [Available at the Business Administration Library.]

Rajagopalan, S., \& Mathew, S. K. (2016). Choice of agile methodologies in software development: A vendor perspective. Journal of International Technology and Information Management, 25(1).

Ramasubbu, N., Bharadwaj, A., \& Tayi, G. K. (2015). Software process diversity: Conceptualization, measurement, and analysis of impact on project performance. MIS Quartery, 39(4), 787-807.

Repenning, N. P., Kieffer, D., \& Repenning, J. (2018). A New Approach to Designing Work. MIT Sloan Management Review, 29-38. Retrieved from sloanreview.mit.edu

Stoica, M., Ghilic-Micu, B., Mircea, M., \& Uscatu, C. (2016). Analyzing agile development - from waterfall style to Scrumban. Informatica Economică, 20(4), 5-15.

Tsai, W. L., Chen, C. Y., \& Chen, C. S. (2018). Snowman: Agile development method with institutionalized communication and documentation for capstone projects. Asia Pacific Management Review, 23(1), 12-19. 


\section{Issues in Information Systems}

Volume 19, Issue 2, pp. 119-131, 2018

Varajão, J. E. (2018). A new process for success management. Journal of Modern Project Management, 92-99. https://doi.org/10.1177/004051755602600608

Weber, J., Förster, D., Stäbler, M., \& Paetzold, K. (2017). Adapt! - Agile Project Management Supported by Axiomatic Design. MATEC Web of Conferences (ICAD 2017), 127(1018).

https://doi.org/10.1051/matecconf/201712701018

Wolfgang, T. (2017). Monte Carlo simulation and agile methods in project risk management. In Project Management Development - Practice and Perspectives: Sixth International Scientific Conference on Project Management in the Baltic Contries, April 27-28, 2017, Riga, University of Latvia (pp. 318-329). 